DOI: $10.35355 / 0000052$

\title{
IDENTIDADE CULTURAL EM TIRADENTES (MG): TRADIÇÃO INVENTADA E LUGARES DE MEMÓRIA
}

\author{
Maria Luiza Almeida Cunha de Castro* \\ Universidade Federal de Minas Gerais - UFMG \\ luizadecastro@ufmg.br \\ Clarissa de Oliveira Neves** \\ Centro Universitário Metodista Izabela Hendrix \\ clarissa.arq@gmail.com
}

\begin{abstract}
RESUMO: As cidades históricas convivem com o conflito entre a tentativa de preservação de seu patrimônio e a necessidade de inserção nas dinâmicas contemporâneas, contrapondo o enraizamento na tradição à "liquidez" que permeia a realidade atual. Este contexto exige a criação de novas identidades, que possam se estruturar dentro da dialética entre o passado e o presente. O objetivo deste artigo é interpretar as transformações pelas quais a cidade de Tiradentes (MG) tem passado, a partir das perspectivas desveladas pelos conceitos de "tradições inventadas" proposto por Hobsbawm e de "lugares de memória", desenvolvido por Pierre Nora. Destaca-se, neste caso, o papel dos festivais e eventos- em especial a Mostra de Cinema - na construção de uma nova identidade, que articula história e contemporaneidade.
\end{abstract}

PALAVRAS-CHAVE: Tiradentes - Identidade -Tradição Inventada - Lugar de Memória - Mostra de Cinema

\section{CULTURAL IDENTITY IN TIRADENTES (MG): THE INVENTION OF TRADITION AND SITES OF MEMORY}

\begin{abstract}
Historical cities must deal with a conflict between the attempt to preserve their heritage and the need of insertion in a contemporary dynamic, opposing the rooting in tradition to the "liquidity" that pervades reality nowadays. This context requires the creation of new identities, which may be structured within the dialectic between the past and the present. The purpose of this paper is to interpret the transformations the city of Tiradentes (MG) has undergone, from the perspective provided by the concepts of "invented traditions", proposed by Hobsbawm and "site of memory", developed by Pierre

Doutorado em Ciências Sócio Ambientais pelo Núcleo de Altos Estudos da Amazônia (UFPA). Atualmente é professor adjunto, atuando junto à Universidade Federal de Minas Gerais. Professora permanente do Programa de Pós-graduação PACPS -UFMG

** Mestre pelo Programa de Pós-graduação PACPS -UFMG. Atualmente é associado - WN Escritório de Arquitetura e Cenografia e professora do curso de Arquitetura e Urbanismo.
\end{abstract}


Disponível em: www.revistafenix.pro.br

Nora. It highlights the role of festivals and events in the construction of a new identity for the city - with emphasis on the Cinema Show - capable of articulating history and contemporaneity.

KEYWORDS: Tiradentes - Identity - Invention of Tradition - Site of Memory - Cinema Show

\section{CONSTRUINDO A IDENTIDADE: LUGARES DE MEMÓRIA E TRADIÇÕES INVENTADAS}

Assim como outras cidades históricas, Tiradentes (MG) tem sofrido, desde o início do século passado, pressões de uma dialética que se estabelece entre a preservação de seu patrimônio cultural e a necessidade de inserção dentro das dinâmicas contemporâneas. A ideia de preservação do patrimônio se desenvolveu, inicialmente, em torno de propostas de construção de uma identidade para o país, tema considerado de interesse público.

Entretanto, na nova fase da modernidade, descrita por Bauman como "líquida", a identidade baseada em referências do passado não parece mais ser viável: "[...] esses referentes de identificação, historicamente mutáveis, foram embalsamados pelo folclore em um estágio 'tradicional' de seu desenvolvimento, e foram declarados essência da cultura nacional" (CANCLINI,1999, p. 145). Não conseguem, porém, assegurar a vitalidade, gerando espaços que funcionam como verdadeiros museus, legitimando valores desatualizados. A razão desta defasagem está no fato de que sentimentos e fatores compartilhados - língua, objetos, costumes - que antes diferenciavam os habitantes de um território - foram relativizados pela realidade atual, que está na origem desta crise (CANCLINI, 1999). As organizações sociais e instituições não são mais capazes de assegurar uma continuidade ou de se colocar como "arcabouços de referência para as ações humanas" (BAUMAN, 2007, p. 07), pois sua forma não se mantém por muito tempo e se decompõe, liquefazendo-se.

Este contexto impõe, portanto, a construção de novas identidades, para que as comunidades não se desintegrem. Em lugares em que os elementos ligados à tradição e às origens não são mais suficientes para criar uma dinâmica local pertinente, a identidade pode ser elaborada, não como uma "essência intemporal que se manifesta, mas como uma construção imaginária que se narra" (CANCLINI, 1999, p. 148): uma identidade de destino, em oposição a uma identidade baseada na origem. De acordo com Bauman: “A identidade só nos é revelada como algo a ser inventado, e não descoberto; 
como alvo de um esforço, "um objetivo", como uma coisa que ainda se precisa construir a partir do zero ou escolher entre alternativas”. (BAUMAN, 2005, p.21-22)

A partir desta concepção, a identidade, provisória e parcial, aberta à construção de uma nova história (LACLAU apud HALL, 2006), deve ser sempre atualizada, como "um relato que reconstruímos incessantemente". Ela precisa envolver articulações com o presente e com o futuro para se tornar uma "coprodução", portadora de sentidos artísticos, folclóricos, comunicacionais, políticos e sociais.

Tiradentes tem assistido, portanto, a tentativas deliberadas de construção de uma nova identidade, sem esquecer, porém, a importância de seu espaço enquanto patrimônio histórico. Este processo tem contado com iniciativas do poder público, mas também de indivíduos influentes e têm envolvido, ao longo do tempo, estratégias para manipulação de características e requisitos simbólicos (ONO, 2006) como as descritas por Hobsbawm (1997) - as “tradições inventadas" - ou por Nora (1997) - os "lugares de memória".

As tradições inventadas partem da criação de "práticas de natureza ritual ou simbólica", que não existiam anteriormente, mas foram criadas com o intuito de inculcar, revelar, valores e normas de comportamento. Elas procuram se contrapor "às constantes mudanças e inovações" e estruturar a realidade "de maneira imutável", estabelecendo-se "através da repetição". Constituem uma prática comum, e muitas das tradições consolidadas atualmente na sociedade, consideradas antigas, são recentes. Quer sejam "inventadas, construídas e formalmente institucionalizadas" ou surjam de forma mais indefinida, são "tradições inventadas". (HOBSBAWM, 1997, p. 09)

A criação de "lugares de memória", por sua vez, é um artifício para lidar com uma oposição entre o lembrar e o esquecer, para cristalizar determinadas memórias escolhidas. Nora (1997) parte do princípio de que não há memória espontânea, sendo, portanto, preciso criar recursos para salvaguardar lembranças - exatamente pelo fato de elas não estarem efetivamente presentes. A história, que é uma narrativa construída, se apodera do que ele chama de "lugares" - mas podem ser símbolos, eventos, instituições, etc - fazendo deles o receptáculo destas memórias escolhidas. Os lugares de memória podem ser materiais ou virtuais e traduzem uma "vontade de memória" (NORA, 1993, p. 22), surgem do desejo de salvaguardar aquele aspecto específico.

Em Tiradentes, os conceitos de "tradição inventada" e "lugar de memória" se entrelaçam com um novo repertório de significados, ajudando a compreender o contexto 
Disponível em: www.revistafenix.pro.br

da construção deliberada de uma identidade contemporânea. A cidade é, hoje, considerada um destino indutor de turismo mineiro e nacional (BRASIL, 2018-2022) e percebe-se em seu espaço uma justaposição de elementos de história e de contemporaneidade, mesmo que de forma fragmentada. Neste sentido, adquirem especial destaque os eventos e festivais que repercutem diretamente no turismo, economia e paisagem locais, reverberando as iniciativas de criação e/ou cristalização de passados.

Estes processos de manipulação de requisitos simbólicos são controversos e muitas vezes são criticados pelo fato de serem uma tentativa de "ressemantização de estruturas vazias com os novos ícones da florescente indústria de cultura de massa". Entretanto, no caso de Tiradentes, os festivais, que passaram a fazer parte da rotina da cidade, têm contribuído para trazer vida e conteúdo cultural com novos sentidos para a dinâmica local: o passado se articula, desta forma com a realidade atual, colocando-se como uma "abertura para a sociedade", como recomenda Santos. (SANTOS, 2001, p.46)

O objetivo deste artigo é propor uma interpretação das transformações pelas quais a cidade de Tiradentes (MG) tem passado, situando os eventos e festivais como elemento de articulação da cidade com o tempo atual. Para isso, a revisão bibliográfica realizada evoluiu a partir da investigação de um contexto no qual as tradições anteriormente compartilhadas na cidade foram dissolvidas e relativizadas pela globalização e pelo dinamismo da contemporaneidade - tal como descrevem Hall (2006), Canclini (1999), Nora (1997) e outros. Para subsidiar a análise foi feito um levantamento de dados primários, por meio de pesquisa documental e entrevistas, incluindo ainda a observação participante. A partir de um olhar perspectivado, tomando como base um diálogo entre as questões levantadas e as categorias teóricas propostas, o trabalho procurou situar os eventos e festivais como elemento de articulação da cidade com o tempo atual. Demonstra-se, assim, as possibilidades que trazem para a construção de novas memórias, o que permite que identidade local não se restrinja à história, conforme recomenda Hobsbawm (1997).

\section{TIRADENTES: PREENCHENDO AS LACUNAS DE UMA HISTÓRIA EM CONSTRUÇÃO}


Importante centro de exploração de ouro no século XVIII, a Vila São José do Rio das Mortes entrou no século seguinte em processo de decadência devido ao esgotamento da atividade. O primeiro indício de uma tentativa de criação de valor simbólico para a já então cidade de São José del-Rei, foi a mudança de seu nome para Tiradentes, em 1889, em uma alusão emblemática ao alferes Joaquim José da Silva Xavier, nascido na região, um dos principais protagonistas da Inconfidência Mineira. A jovem república utilizava-se deste artifício como parte de uma estratégia de criação de heróis nacionais, procurando inculcar valores que representassem os novos ideais. A cidade, por sua vez, buscava, no passado, referências que pudessem ajudar na transição para uma nova e difícil etapa de sua trajetória, revelando sua predisposição para a "tradição inventada".

No início do século XX, era latente uma preocupação com a consolidação de uma nação brasileira, face à grande massa de imigrantes e à ocupação desigual do amplo território, cheio de vazios demográficos (VELLOSO, 1993). Neste sentido, o debate intelectual que se instaurou deu centralidade à questão da identidade nacional, capaz de gerar um sentimento de pertencimento e de nacionalismo. Ele foi reforçado pelo movimento modernista, manifestando-se no país como "uma linha de indagações sobre o ingresso da produção artística brasileira na ordem da modernidade" (MORAES, 1988, p. 221). Por volta de 1924, o movimento chegou à definição do próprio conceito de modernidade para o caso brasileiro, entendendo que a "brasilidade" era o tema central para o projeto modernizador. Desta forma, valores ligados à tradição ganharam destaque, fortalecidos pela ideia de que "a obra moderna há de "se extrair da obra dos antepassados". (MORAES, 1988, p. 222)

Em 1924, os modernistas Mário de Andrade, Tarsila do Amaral e Oswald Andrade, em uma programação que propunha apresentar o Brasil ao francês Blaise Cendrars, visitaram Tiradentes: a viagem ficou conhecida como a "redescoberta do Brasil pelos modernistas" (RIBEIRO, 2005, p. 77). Eles se encantaram com o legado colonial, enquanto elemento que determinava a distinção do país com relação a outras culturas, base para a identidade que buscavam. Na imagem que construíam, a arquitetura desempenhava papel central, uma vez que era um subsídio material para o sentimento subjetivo que buscavam consolidar: em suas manifestações, eles enalteciam "[...] ] cor-de-rosa das fachadas, o abrigo dos beirais e o azul das janelas - nascidos da 
Disponível em: www.revistafenix.pro.br

paisagem brasileira e da tradição, e tão naturalmente de acordo com elas". (ANDRADE apud RIBEIRO, 2005, p. 79)

Esta viagem representou o despertar para o potencial da região de Tiradentes, a partir da produção simbólica de uma identidade baseada exatamente na apropriação do passado para incorporar tradições e costumes à história em construção (NEVES; CARNEIRO, 2014) - um lugar de memória.

Esta tendência de recorrer ao patrimônio como âncora para uma identidade nacional em construção foi intensificada no governo Vargas (FONSECA, 1997). Nesta época, o contexto de resgate do patrimônio construído atraiu para Tiradentes os olhares do recém criado SPHAN - Serviço do Patrimônio Histórico e Artístico Nacional, (atualmente IPHAN) - que, em 1938, dois anos após sua criação, tombou o conjunto arquitetônico e urbanístico da cidade. As diretrizes de tombamento da época criavam, entretanto, uma articulação em torno de uma ideia de preservação, de “caráter essencialmente imobilista, tendo como foco, de fato, a limitação da mudança". (CASTRIOTA, 2013, p. 12)

A rigidez deste olhar não foi efetivamente aplicada, uma vez que não havia, inicialmente, recursos para o monitoramento e fiscalização nem preservação material das áreas tombadas. Desta forma, muitos edifícios existentes continuaram a se deteriorar (NEVES, CARNEIRO, 2014), ao mesmo tempo em que novas edificações foram erguidas sem qualquer restrição de estilo, material ou técnica, ou de busca de "harmonia do conjunto colonial'". (MADUREIRA, 2011, p. 58)

Nas décadas de 1960 e 1970, as diretrizes de construção se tornaram mais definidas - embora dentro de um padrão pelo qual "a estética prevalecia sobre o documental” (MADUREIRA, 2011, p. 58). Surgiram novas construções que, muitas vezes - mas nem sempre - configuravam um "estilo patrimônio", comum também em outras cidades. Os vazios urbanos foram aos poucos sendo ocupados por edificações “miméticas" (MADUREIRA, 2011, p. 58), inclusive em um dos locais que se tornava um dos mais emblemáticos da cidade, o Largo das Forras. A narrativa da preservação se articulou, assim, em Tiradentes, com falhas e fissuras, gerando lacunas que foram sendo preenchidas com "tradições inventadas", por meio de “[...] empréstimos fornecidos pelos depósitos bem supridos de rituais do passado, ou mesmo, por enxerto em velhas tradições”. (HOBSBAWM, 1997, p. 14) 
Disponível em: www.revistafenix.pro.br

Porém, a identidade configurada ao longo dos anos, ainda que baseada em valores que não mais existiam - ou nem tinham existido - permitiu que a cidade, em seu conjunto, fosse, aos poucos, se consolidando como um "lugar de memória" (NORA, 1997) - parte de uma história construída para organizar o passado e salvaguardar lembranças escolhidas. A relação com o passado, embora frágil, aliou-se às condições favoráveis do local (tranquilidade, bucolismo, situação geográfica privilegiada), atraindo novos moradores, subsidiando uma lenta, porém gradativa, criação de valor simbólico.

Para a aceleração deste processo, foi primordial o fenômeno que Bourdieu (1998) chama de "descoberta", viabilizado pela intervenção de formadores de opinião que dão credibilidade a uma ideia, emprestando a ela sua "autoridade cultural". A consagração que estes "descobridores" conseguem promover é "[...] tão mais importante" quanto mais eles forem eles mesmos consagrados, disponibilizando "todo o capital simbólico" que acumularam.

Assim, teve início uma segunda etapa de criação de valor simbólico para a cidade - depois da descoberta pelos modernistas na década de 1920 - com a intervenção, agora, de novos "descobridores", detentores de elevado capital cultural, cuja atuação foi decisiva para o efetivo estabelecimento de Tiradentes enquanto "lugar de memória". Neste sentido, destacou-se o então governador de Minas Gerias, Israel Pinheiro, que esteve à frente de diversas iniciativas. Uma delas foi a construção da BR 265 - obra inaugurada em 1968, que ligou a cidade a São João del-Rei e Barbacena; de grande importância foi também a mobilização que promoveu entre os intelectuais, envolvendo outras personalidades em torno de uma reconfiguração da cidade - como a socialite carioca Maria do Carmo de Mello Franco Nabuco. Maria do Carmo conseguiu recursos da iniciativa particular para a restauração de edificações, participando, ainda, da criação, em 1970, da Fundação que levou o nome de seu primo, Rodrigo Melo Franco de Andrade ${ }^{1}$ (NEVES; CARNEIRO, 2014, p.418).

Moradores influentes também foram atraídos para a cidade nesta época e se tornaram importantes artífices da sua redinamização. Entre outros, destaca-se um grupo

1 A Fundação Rodrigo Mello Franco de Andrade tem, desde então, “contribuído de forma sistemática para a recuperação e conservação do Patrimônio de Tiradentes" Disponível em: https://www.ufmg.br/frmfa/inicio. 
de intelectuais, que na década de $1980^{2}$, criou a Sociedade dos Amigos de Tiradentes, responsável por diversas iniciativas de valorização do patrimônio: entre elas, o projeto "Obras Emergenciais" que recuperou edifícios em ruínas e instalou sistema de eletricidade subterrâneo, resgatando a tradição e a imagem do passado.

Ainda neste período, o Plano de Reorganização Espacial do Circuito do Ouro do Campo das Vertentes da Fundação João Pinheiro, com foco no desenvolvimento do turismo, sugeriu intervenções em edificações que considerava estar em conflito com o núcleo antigo, incluindo adequação de fachadas, afastamentos laterais e frontais. Além disso, o plano também definiu critérios para futuras construções. (MADUREIRA, 2011, p. 58)

Dentro desta perspectiva, o sentido material da ideia de instituição de Tiradentes enquanto lugar de memória se exprimiu na reconfiguração das construções e do espaço da cidade; seu caráter simbólico, por sua vez, trouxe à tona a narrativa referente ao período colonial, selecionada para se tornar suporte da imagem desejada, refletindo uma visão ligada ao passado. Por fim, seu sentido funcional cumpriu o papel de cristalizar a lembrança deste passado escolhido. Estes três aspectos são característicos dos "lugares da memória", capazes de criar um jogo entre a memória e a história, cujo papel principal é parar o tempo, bloquear o esquecimento, materializar o imaterial; enfim, resolver a dialética entre o esquecer e o lembrar (NORA, 1993). Dessa forma, os vestígios do passado, testemunhos de outros tempos, de outras realidades, materializaram, na cidade, a nostalgia de lembranças afetivas de uma sociedade que deixava de criar as suas memórias para sacralizar o passado, deixava de viver verdadeiramente as suas próprias lembranças para visitar os lugares da memória.

Entretanto, passado, tradição e origens não são suficientes para consolidar a dinâmica do presente (CANCLINI, 1999), sendo necessário que estabeleçam um diálogo com o novo, para que a fruição do espaço vá além da história. Tiradentes enquanto lugar de memória, assumiu um novo significado, quando as mesmas características exploradas para reviver a história tornaram-se uma plataforma capaz de configurar novas possibilidades de vivência. Na etapa seguinte de transformação da cidade, este ambiente se materializou como cenário para a realização de filmes, séries e

2 Yves Alves, diretor da rede Globo Minas, a partir de 1982; John Parsons, ecologista e engenheiro inglês, proprietário do Hotel Solar da Ponte; Joaquim Falcão, atual diretor da Escola de Direito da Fundação Getúlio Vargas, na cidade do Rio de Janeiro e Ângelo Oswaldo, jornalista, escritor e advogado, curador de arte e político. (NEVES; CARNEIRO, 2014, p. 418) 
Disponível em: www.revistafenix.pro.br

novelas e, paradoxalmente, o espaço de ficção se desdobrou em novas dimensões que alimentaram o espaço real.

\section{CENÁRIO PARA UM TEMPO "PERMANENTE": A BRASILIDADE ENRAIZADA NA TRADIÇÃO}

Segundo Neves e Carneiro (2014), o processo de criação de valor simbólico, baseado no passado colonial, converteu Tiradentes em cidade-mercadoria, com uma imagem de "autêntica cidade histórica do século XVIII e XIX" (NEVES; CARNEIRO, 2014, p. 72). Foi atraída por este contexto que a Rede Globo de televisão passou a utilizá-la como locação para suas novelas e minisséries. É interessante observar, entretanto, que nenhum dos enredos levados à tela se passava originalmente em Tiradentes, ou no período colonial - as narrativas não possuíam qualquer vínculo com a história local, estando, sim, ligadas à brasilidade atemporal que a cidade conseguia sintetizar. O valor simbólico engendrou, desta forma, uma rede de relações visíveis e invisíveis que foi aos poucos se consolidando e abrindo perspectivas para articulações inesperadas.

A primeira gravação que projetou a cidade no cenário nacional foi o "Memorial de Maria Moura” (1994), baseado na obra homônima de Raquel de Queiroz- ambientada no sertão nordestino do século XIX. Em seguida, dentre outros, houve o longa metragem "Menino Maluquinho" (1995), a partir do livro infantil de mesmo nome, publicado em 1980; a minissérie "Hilda Furacão" (1998), romance de Roberto Drummond, que se passa na Belo Horizonte dos anos 1950; a novela "Coração de Estudante" (2002) da Globo, uma trama contemporânea que se desenvolvia na cidade fictícia de Nova Aliança; a novela da TV Record, "Essas Mulheres" (2005), passada em 1880, na cidade do Rio de Janeiro; e "Chico Xavier, O filme" (2010), sobre a vida do grande expoente do espiritismo que viveu de 1910 a 2002. Mais recentemente, a rede Globo gravou cenas da novela das 18h, "Espelho da Vida" (2018), que contrapões duas épocas distintas - a atualidade e o início do século XX - filmada em Tiradentes e Carrancas. 
Muitas vezes, as filmagens implicavam em alterações no cotidiano da cidade, provocando protestos e transtornos ${ }^{3}$, mas apresentavam compensações em termos de visibilidade e encontravam reverberação nos habitantes, seduzidos, até certo ponto, pelo charme das filmagens. Segundo Ralph Justino ${ }^{4}$, essa visibilidade nacional impulsionou o turismo e contribuiu efetivamente para a construção do valor simbólico local. (SCALZO, 1997)

A flexibilidade do espaço da cidade para a encenação de romances passados em diferentes lugares e épocas demonstra, portanto, a sua abrangência enquanto "lugar de memória" - adaptável, um espelho no qual múltiplos passados podem ser refletidos, projeção de diferentes cotidianos, impregnado de valores caros à identidade brasileira. Ribeiro e Braga (2009) falam da desconstrução da cidade real para dar lugar a uma cidade imaginária, muitas vezes fetichizada, com outra identidade, que não a colonial.

Porém, o que parece ser o ponto em comum entre as narrativas que têm utilizado Tiradentes como pano de fundo é a sua atemporalidade. A imagem criada para a cidade parece acolher qualquer narrativa que reflita um tempo "permanente" "de longa duração e em câmara lenta” (RIBEIRO, 2009, p. 139). Este tempo, segundo Gurvitch, corresponde a formações culturais " [...] que se movem em um mundo de determinações", tais como "[...] os agrupamentos de parentesco e os agrupamentos de localidade, principalmente em meio rural, [que] dizem respeito à classe camponesa e às sociedades patriarcais" (FARRUGIA, 1999, p. 115). Desta forma, Tiradentes apresenta um conjunto de signos - em parte, memória herdada e, em parte, "tradição inventada" (HOBSBAWM, 1997), que permite a sua consolidação como cenário para tramas que envolvam tradição: a busca de uma continuidade entre o passado e o presente foi elaborada por meio de uma imagem tão fluida que ela se constrói de acordo com a necessidade - não só como cidade barroca, mas como cidade do interior, cidade bucólica, cidade que se conforma, tornando-se lugar de várias memórias - todas, porém, ligadas a uma ideia de brasilidade atemporal, a mesma adotada como base para a modernidade no caso brasileiro.

3 Em algumas situações, entretanto, os transtornos provocaram protestos, como no caso da Gravação de "Hilda Furacão", durante a qual "a emissora contrariou normas de conservação de monumento" e "interditou pontos turísticos nos finais de semana", entre outros (SCALZO, 1997)

4 Ralph Justino foi Secretário da Cultura e Turismo e, em 2012, eleito Prefeito da cidade. Natural de Belo Horizonte, foi morar em Tiradentes em 1992 e foi o principal agente da criação do calendário de eventos da cidade, investindo no turismo cultural. 
Disponível em: www.revistafenix.pro.br

Porém, o dinamismo desta conformação impulsionou a identidade local a uma nova etapa de atualização, que lançou mão da "invenção de tradições".

\section{VELHOS MODELOS PARA NOVOS FINS: A INVENÇÃO DOS EVENTOS}

As "tradições inventadas" em Tiradentes tiveram, inicialmente, o objetivo de dar suporte à construção de um "lugar de memória" ligado ao passado colonial. Para isso, estratégias como a troca de nome da cidade e programas de valorização do conjunto urbano foram adotadas, enquanto exaltação simbólica da cidade e da identidade brasileira. Entretanto, novos grupos e contextos que surgiram "[...] exigiam novos instrumentos que assegurassem ou expressassem identidade e coesão social, e que estruturassem relações sociais [...]” e, mesmo, novas dinâmicas espaciais, necessárias a uma "sociedade em transformação". Conforme visto anteriormente, várias das ações ocorridas neste sentido em Tiradentes foram oficiais, promovidas pelo próprio governo, que usava a história como "legitimadora das ações" e como elemento fundamental na “coesão grupal”. (HOBSBAWM, 1997, p. 271)

O recurso à invenção de tradições, que foi coadjuvante nas etapas iniciais de conformação identitária de Tiradentes, assumiu protagonismo a partir da última década do século XX, com a configuração de uma agenda de eventos na cidade.

Todo o contexto de transformação de Tiradentes provocou uma ruptura nos costumes da sociedade local, com a quebra de "vínculos sociais" e geração de vácuos. Esses vazios ficaram disponíveis para serem "preenchidos com tradições inventadas" (HOBSBAWM, 1997, p. 16), um fenômeno que é mais premente quando há uma transformação na sociedade. Ocorre principalmente quando há uma destruição dos padrões sociais e das "velhas tradições" ou quando as "velhas tradições" perdem a capacidade de adaptação e flexibilidade, não correspondendo mais aos novos tempos. (HOBSBAWM, 1997, p. 13)

No caso da promoção de eventos na cidade, foi importante a "utilização de elementos antigos na elaboração de novas tradições inventadas" (HOBSBAWM, 1997, p. 16). Ao longo dos anos uma vida cultural baseada nas manifestações sacras havia sempre sido mantida e novos eventos culturais puderam ser inseridos, assim, dentro de uma atmosfera que propiciava o seu reconhecimento. 
Entre as práticas pré-existentes, destacavam-se as festividades da semana Santa, a veneração à Santíssima Trindade, a comemoração do padroeiro da cidade, Santo Antônio, e a festa de Corpus Christi. Estas festas envolvem representações sacras, procissões e tradições centenárias - como a representação do calvário de Cristo, na Semana Santa, ou a tradição dos ex-votos, na veneração à Santíssima Trindade. A movimentação de fiéis e romeiros também é relevante, chegando, no caso da Santíssima Trindade, a vinte mil romeiros, inclusive de outros estados" (ROMARIA, 2018). Outra tradição importante é a decoração das ruas com os tapetes ornamentais, confeccionados originalmente com serragem, na festa de Corpus Christi. Como festa profana, destaca-se o Carnaval de rua, com bandas e blocos caricatos. Existem ainda as comemorações em homenagem a Tiradentes, o alferes da Inconfidência Mineira que deu o nome a cidade, uma festa que ocorre em abril. Este é um exemplo nítido de tradição inventada - mesmo se já antiga . Mas todos os demais eventos pré-existentes, embora parte das tradições herdadas, foram sendo reinventados ao longo dos anos, em suas especificidades locais. Para Hobsbawm, “[...] provavelmente não há lugar nem tempo investigado pelos historiadores onde não haja ocorrido a "invenção de tradições" (HOBSBAWM, 1997, p. 12).

A existência desta tradição de eventos abriu espaço para a emergência de uma nova geração de invenções. Desta forma, o dinamismo trazido a Tiradentes pelas diversas filmagens e pelo turismo encontrou ressonância na fluidez da identidade contemporânea, mas também nessas comemorações seculares, viabilizando novas articulações. A reafirmação da dialética entre o passado e o presente despertou um tempo social que Gurvitch (1964) entende como "alternado". Trata-se do "tempo das comunidades quando elas sacodem o seu imobilismo", que se impõe quando os grupos procuram novos valores sem poder ainda renunciar aos antigos, e efetivamente escolher". (FARRUGIA, 1999, pp. 95-117)

Por um lado, em um contexto marcado pela busca incessante da valorização cultural, novos eventos culturais se acomodaram lado a lado com as tradições inventadas ou não - em um arranjo que incluiu elementos da história, mas também de memória. Por outro lado, a efemeridade dos eventos fez com que eles se encaixassem perfeitamente em um ambiente mutável, ambivalente, adaptável, que privilegia a dinâmica de processos, mais do que formas de expressão mais estáticas. (CANCLINI, 1999, p. 129). 
$\mathrm{Na}$ tentativa de sincronização com a dinâmica de um tempo "acelerado" (GURVITCH, 1964, p.27-30) e com a realidade mutante, os novos estados da consciência humana, em sua transformação, têm demonstrado necessidade de interação (CANCLINI, 1999). Assim, a arquitetura efêmera, em sincronia com o dinamismo e velocidade da experiência contemporânea, conseguiu repercutir de novas maneiras no contexto urbano e produzir a ressignificação do espaço. A criação de uma agenda de eventos em Tiradentes se colocou, dessa forma, como estratégia estruturada de invenção de tradição, buscando elementos pré-existentes, reconhecíveis - os eventos religiosos locais e o caráter de lugar de memória - e associando-os a tendências sociais contemporâneas, reflexo de um tempo acelerado, para consolidar as práticas culturais.

Os novos eventos inventados, que aos poucos vêm se transformando em tradição, assumiram a forma de mostras e festivais, e têm se articulado por meio da abertura de novas possibilidades de vivências e práticas permeadas por experiências culturais como o cinema, a gastronomia e o esporte.

Os temas dos festivais locais são variados, com diferentes estilos e programações e mobilizam públicos específicos. Assim, propiciam uma experiência intelectual, emocional, afetiva única, ao mesmo tempo em que se articulam também com o espaço da cidade. Por um lado, existe uma imagem dal cidade, enquanto "destino", (dentro de uma perspectiva de turismo), que inclui crenças, conhecimentos, mas também os sentimentos que os visitantes desenvolvem em relação a ela. Por outro lado, esta imagem se conjuga à imagem do evento que "[...] reflete o significado do evento para o indivíduo". Tanto a imagem do destino quanto a imagem do evento são construídas por meio de percepções que se refletem em representações racionais e afetivas e as duas se influenciam mutuamente. Eventos e cidades podem, desta maneira, reforçar mutuamente sua percepção positiva. (SANTOS; ZUCCO: KRAUS, 2015, p. 133)

A imagem da cidade e as imagens dos eventos se articularam em Tiradentes, a cultura local se atualizou e continua em movimento, buscando referência na contemporaneidade e na diversidade, em oposição à imagem imobilista de patrimônio. A Mostra de Cinema, a primeira a ser implantada no local, é exemplar neste sentido.

\section{A Mostra de Cinema Como ponto de articulação}


Disponível em: www.revistafenix.pro.br

Não é coincidência que a Mostra de Cinema tenha se colocado como um dos principais pontos de articulação entre a cidade histórica e a cidade contemporânea - e promovido as condições necessárias para que outros eventos efêmeros aí se instalassem em Tiradentes. A inserção deste evento ocorreu a partir da consolidação de um ambiente de cenário pelas redes midiáticas nacionais, trazendo à tona referências de cultura popular e a nostalgia dos áureos tempos em que os espetáculos eram o centro da vida social das cidades do interior do Brasil. A Mostra lançou mão do apelo à memória de forma explícita, utilizando lonas de circo nas primeiras edições, trazendo referências lúdicas à tradição dos espetáculos itinerantes, de duração efêmera, para associar tais valores às novas atividades propostas. A inserção do cinema em uma cidade que nunca tivera uma sala de exibição também trouxe o encantamento da tela grande para os moradores locais e, em uma segunda fase, a referência passou a ser o próprio cinema. Outro elemento que foi aproveitado para enraizar as novas práticas foi a tradição de receber e movimentar fiéis em torno de festas religiosas e procissões sacras e do carnaval, recriada no "Cortejo das Artes", uma iniciativa que faz parte da programação desde a primeira edição, com banda de música, palhaços e artistas de rua. (HALLAK, 2018).

A Mostra de Cinema de Tiradentes completou, em 2019, vinte e duas edições. Realizada na segunda quinzena de janeiro, inaugura a temporada de audiovisual no Brasil e conquistou, ao longo destes anos, um lugar de destaque no circuito das mostras e festivais deste gênero. Sua programação inclui a exibição de filmes inéditos, lançamentos, mostras temáticas, retrospectivas, além de oficinas para a formação profissional, debates com diretores e atores, lançamentos de livros, shows e performances. (CATÁLOGO MOSTRA, 2017)

A ideia partiu da Universo Produção, atendendo a uma demanda da Prefeitura de Tiradentes, que estudava estratégias capazes de impulsionar o turismo local. A cidade estava despontando para o turismo devido às filmagens de novelas e seriados ${ }^{5} \mathrm{e} a$ prefeitura, entendendo o cinema como parte do repertório ativo local, procurava promover o desenvolvimento, investindo em atrações para o público vinculado ao tema.

\footnotetext{
5 Naquela época, Tiradentes ainda não tinha uma agenda de eventos e a cidade tinha alcançado um destaque nacional e começado a construir seu valor simbólico com a realização da série de televisão Hilda Furacão.
} 
Raquel Hallak (2018 $)$ sócia da Universo, viu na proposta da Prefeitura uma oportunidade de ir além da sua demanda, elaborando um projeto maior, que também contemplasse a inauguração de um Centro Cultural idealizado por Yves Alves ${ }^{6}$, até então sem destino definido.

Ralph Justino acredita que o lançamento da Mostra foi o primeiro passo para a transformação da cidade histórica, colonial, em uma das principais cidades turísticas do estado, projetando-a nacionalmente na mídia e trazendo turismo de qualidade (TORRES, 2015). A receptividade por parte da comunidade e também por parte da Imprensa nacional foi muito boa, incentivando a prefeitura a apoiar em seguida o Festival Gastronômico que teve a sua $1^{\circ}$ edição ainda em 1998, seis meses após a Mostra de Cinema.

Sobre a recepção na imprensa, o jornalista Pablo Pires ${ }^{7}$ relata que: “A Mostra de Tiradentes foi a mais bem-sucedida iniciativa de promoção do cinema nacional em Minas, resultando em uma série de desdobramentos positivos e que fomentam o audiovisual local e nacional" (PIRES, 2018) Com edições anuais, sempre no mês de janeiro, e consecutivas, desde a sua criação em 1998, o festival entrou para o calendário do cinema nacional e também inaugurou o calendário de eventos hoje existente na cidade. A agenda é intensa e mobiliza diferentes segmentos, além do cinema.

Em março, desde 2011, acontece o Festival de Fotografia, que busca divulgar a produção fotográfica brasileira. Inclui programas como exposições, workshops e palestras, procurando fomentar o desenvolvimento da linguagem artística brasileira.

O TremBier, criado em 2012 pelo chef Luis Cesar Costa, é um evento dedicado à cerveja artesanal. Acontece em abril e vem crescendo a cada ano na cidade, oferecendo palestras, cursos e stands de cerveja.

Em maio, a cidade recebe a mostra de Artes Cênicas, Tiradentes em Cena, criada em 2013. Esta mostra busca mobilizar e revitalizar espaços, por meio de

6 O Centro Cultural foi idealizado por Yves Alves que através da SAT - Sociedade dos amigos de Tiradentes, com o apoio da Prefeitura, que é a dona do terreno onde foi construída a sede, e com o patrocínio da Fundação Roberto Marinho através da Lei federal de Incentivo a Cultura e da Rede Globo Minas. A inauguração ocorreu em janeiro de 1998 e em 2009 passou a ser administrado pelo Sesi/Fiemg. (FIEMG, 2013.)

7 Pablo Pires era jornalista do caderno Magazine do jornal O Tempo, tendo participado do evento durante várias edições desde a sua abertura. Atualmente é subeditor do Caderno de cultura do jornal Estado de Minas e responsável pelo caderno. Pensar. Entrevista à autora, por escrito (via e-mail), em nov. 2018. 
espetáculos adultos e infantis em edifícios históricos, oferecendo ainda oficinas e rodas de conversa. ${ }^{8}$

O BikeFest Tiradentes, um encontro de motos, é o festival mais antigo da cidade e, ao contrário dos eventos descritos anteriormente, tem um foco mais comercial, dispondo de uma área de comercialização de equipamentos e motos. Gera importante movimentação financeira - em 2016, mais de R $\$ 12$ milhões de reais e acontece na segunda quinzena de junho, com tendas para as marcas expositoras, praça de alimentação e apoio logístico aos motoqueiros.

Em agosto, o Festival de Cultura e Gastronomia de Tiradentes ${ }^{9}$ movimenta a cidade. Criado no mesmo ano da primeira Mostra de Cinema, 1998, pelo então secretário da Cultura e Turismo, Ralph Justino, o festival possui uma programação variada com chefs renomados, envolvendo aulas-show, aulas teóricas, restaurantes, eventos gastronômicos, degustações e apresentações musicais. O evento ocupa três espaços da cidade e estima-se que, na edição de 2018, tenha alcançado um público de vinte e cinco mil pessoas, durante dez dias (ESTADO DE MINAS, 2018). O evento foi um dos pioneiros em alta gastronomia, ajudando a divulgar a comida mineira e também a cidade de Tiradentes. A programação é gratuita, mas os festins e jantares têm entrada paga e diversos tipos de produtos ligados à alimentação são comercializados em barracas.

Em setembro, acontece o Festival Artes Vertentes, criado em 2012. Os idealizadores propõem uma programação com integração de vários campos da arte, estimulando o diálogo entre a arte visual, música, dança, literatura, teatro e cinema. Destaca-se, neste contexto, a ação cultural, desenvolvida por meio de atividades e aulas junto às comunidades locais, "contemplando prioritariamente regiões de vulnerabilidade sociocultural e educacional" durante todo o ano. ${ }^{10}$ (ARTES VERTENTES, 2012)

8 O Festival é realizado com os benefícios da Lei Federal de Incentivo à Cultura e a maior parte da programação é gratuita, embora alguns espetáculos tenham entrada paga.

9 A partir de 2011 o festival passou para a gestão de Rodrigo Ferraz e atualmente faz parte da Plataforma Fartura - Comidas do Brasil, que promove vários festivais além das expedições realizadas por todo o Brasil com o objetivo de valorizar a gastronomia nacional. "(FARTURA BRASIL, 2017)

10 O festival está ligado a uma associação que promove oficinas com crianças, a partir de recursos das doações recebidas e também recebe o apoio da Secretaria Municipal de Educação e do SESC e SESI. Os concertos e espetáculos cênicos têm entrada paga, com preços populares, e as exposições e performances ao ar livre são gratuitas. 
Disponível em: www.revistafenix.pro.br

Também ligado à música, um evento de menor porte, mais intimista, acontece em novembro desde 2008: o Duo Jazz Festival. Ele atrai um público de aproximadamente três mil pessoas, com apresentações nas praças, bares e espaços culturais da cidade.

Além desses eventos, há também outros menores, sazonais, que se distribuem ao longo do ano. O turismo é responsável por $80 \%$ da arrecadação do município e o segmento voltado para os eventos é o seu principal foco, de maneira que o poder público local tem investido e incentivado esta atividade, preenchendo o calendário com atrações todos os meses. Segundo Ralph Justino, a capacidade de realização de eventos nos espaços públicos da cidade está no seu limite, devidos aos impactos das montagens e desmontagens e dos próprios eventos em si. Eles são fundamentais para a sobrevivência da cidade - a arrecadação média por evento é de cerca de 2,5 milhões de reais - porém, é preciso ter cuidados com os problemas estruturais para o espaço público, direcionando os esforços para atrair um público que também valorize o patrimônio e ajude a preservar a cidade. (JUSTINO, 2015)

Do ponto de vista da legislação, existe, portanto, uma preocupação crescente com os impactos, que se reflete, por exemplo, na Lei Municipal № 2.622/2011 que dispõe sobre a realização de eventos de grande porte no município. Além disso, tem sido preconizada a utilização de áreas fora dos setores de atuação do IPHAN, prevista no Plano Diretor Participativo do Município em consonância com a Nota Técnica No 01/2014 - IPHAN/BA (IPHAN, 2014), que fornece orientações quanto a eventos e instalações autorais em bens e conjuntos tombados e em sua vizinhança (BONUTI, 2016). A ocupação do Largo da Rodoviária pelas atividades tem sido, portanto, incentivada.

\section{CONSIDERAÇÕES FINAIS: MATERIALIZANDO A DIALÉTICA ENTRE A HISTÓRIA E A CONTEMPORANEIDADE}

A sociedade contemporânea, muitas vezes arrancada de sua memória pela aceleração das transformações pelas quais passa, tenta se compreender historicamente. Todos sentem a necessidade de ir à busca de sua própria constituição, de encontrar suas origens. A passagem da memória para a história obrigou cada grupo a redefinir sua identidade pela revitalização de sua própria história. (NORA, 1997) 
Com o fim do ciclo do ouro, Tiradentes sofreu um processo de ruptura de forma marcante e, para se reencontrar, transformou-se em lugar de memória. Inicialmente, sob a égide de um sentimento nacionalista, promovido seja pelos governos republicanos, seja pelos intelectuais modernistas, a cidade se ancorou na tradição e na história, dentro de uma narrativa de brasilidade. O objetivo era consolidar uma tradição inventada, suporte para a imagem que o país procurava construir - que se refletiu na preservação de um conjunto urbano barroco supostamente "homogêneo", cujas lacunas foram preenchidas de acordo com a necessidade da narrativa.

Com o apoio de pessoas influentes, o valor simbólico deste espaço foi sendo construído conforme uma imagem de tradição, de acordo com uma dinâmica de tempo imutável, "permanente” (GURVITCH, 1964), gerando, desta forma, um ambiente atemporal, palco para todas as encenações de uma brasilidade desejada, lugar de várias memórias.

Este ambiente possibilitou que a cidade se promovesse, emprestando sua imagem a diversas tramas de cinema e televisão. A nova identidade poderia ter se estabilizado como tal, porém, pressionada pela dialética entre o passado e o presente, e sem poder renunciar aos antigos valores, articulou-os com novas possibilidades. $\mathrm{O}$ primeiro veículo desta articulação foi a continuidade construída entre a função que exercia, enquanto cenário para os diversos filmes, e a promoção de atrações vinculadas ao tema, por meio da Mostra de Cinema. O sucesso da iniciativa, fundado também na preexistência de eventos tradicionais, permitiu uma outra conexão, desta vez, entre este primeiro evento e outros festivais e manifestações culturais. A cidade ganhou, desta forma, uma dinâmica em sintonia com uma identidade contemporânea em crise fragmentada, mutável e cambiante (HALL, 2006) - entre o enraizamento e a efemeridade.

Assim, Tiradentes, que até então se organizava em torno da elaboração de "lugares de memória", com foco no passado, encontrou nos festivais e nas mostras um mecanismo de articulação com a contemporaneidade, capaz de dar suporte à construção de uma identidade atualizada.

Os eventos que são realizados na cidade têm contribuído para esta nova imagem: enquanto expressão de cultura, fomentam o turismo; enquanto cotidiano vivido, espontaneamente atualizado, constituem a verdadeira memória. Por sua vez, a cidade oferece aos eventos sua imagem cuidadosamente construída, um "receptáculo de 
Disponível em: www.revistafenix.pro.br

memórias escolhidas" (NORA, 1997), uma história elaborada, que resulta em significados e percepções positivas para moradores e visitantes: as referências históricas associadas aos eventos permitem que estes indivíduos construam suas próprias memórias.

Tais articulações não acontecem sem fissuras e tensões entre os vários agentes que engendram esta invenção coletiva. Os festivais, com suas estruturas temporárias ocupam os espaços públicos da cidade, gerando impactos no espaço urbano, fazendo com que ele seja transformado, e passe a ser vivenciado pela população local de forma diferente do cotidiano. Se houve melhorias na economia e na arrecadação fiscal, nos acessos e nos cuidados com a manutenção do patrimônio, também são evidentes os efeitos negativos, como a gentrificação, o crescimento desordenado das áreas periféricas (CAMPOS, 2012), as dificuldades de circulação, a insuficiência de infraestrutura (como banheiros públicos), o lixo nas ruas e os incômodos à população, gerados pelos eventos.

A cidade se afirma, porém, dentro de um contexto globalizado, efêmero e fragmentado, sob a forma de redes de sociabilidade intercruzadas, envolvendo processos materiais e imateriais, endógenos e exógenos, tradicionais e contemporâneos. Os problemas que surgem são inerentes a uma dinâmica contemporânea, e refletem, em Tiradentes, a dialética que os engendra, contrapondo memória - "um fenômeno sempre atual" - e história - "uma representação do passado". (NORA, 1997)

A narrativa que se constrói é, portanto, duplamente legitimada: enquanto reflexo cultural do território e enquanto expressão de contemporaneidade, tal como recomenda Canclini (1999). Resta, porém, lembrar que seu caráter é eternamente precário e inconcluso, o que vai demandar sua renovação incessante (BAMAN, 2005): a realização dos eventos que, dentro de um determinado equilíbrio, representa uma identidade que dá novo sentido e materializa uma estratégia de articulação para a cidade, pode, se levada a extremos, tornar-se a própria catalizadora da sua descaracterização. 


\section{REFERÊNCIAS BIBLIOGRÁFICAS}

ANDRADE, 1991 apud RIBEIRO, Monica Cristina. Arqueologia modernista: viagens e reabilitação do primitivo em Mário e Oswald de Andrade. 2005. Dissertação (Mestrado em Antropologia Social) - Universidade Estadual de Campinas.

BAUMAN, Zygmunt Tempos Líquidos. Rio de Janeiro: Jorge Zahar. 2007.

BAUMAN, Zygmunt. Identidade: entrevista a Benedetto Vecchi. Rio de Janeiro: Jorge Zahar 2005.

BOURDIEU, Pierre. Le marché des biens symboliques. In: BOURDIEU, Pierre. Les règles de l'art : genèse et structure du champ littéraire. Paris: Éditions du Seuil , 1998.

BONUTI, Luciana. Paisagem urbana e conservação: Análise crítica das instalações provisórias em Tiradentes/MG. In: COLÓQUIO IBERO-AMERICANO PAISAGEM CULTURAL, PATRIMÔNIO E PROJETO, 4. 2016. Belo Horizonte Anais... Belo Horizonte: UFMG, 2016

CAMPOS, Helcio Ribeiro. Espaço urbano e turismo em Tiradentes-MG. Espaço Acadêmico, v. 11, n. 132, p. 182-191, 2012.

CANCLINI, Nestor G. Consumidores e cidadãos: conflitos multiculturais da globalização. $4^{\circ}$ ed. Rio de Janeiro: Ed. UFRJ, 1999.

CASTRIOTA, Leonardo Barci. Intervenções sobre o patrimônio urbano: modelos e perspectivas. In: FÓRUM PATRIMÔNIO: AMBIENTE CONSTRUÍDO E PATRIMÔNIO SUSTENTÁVEL, 1., 2013. Belo Horizonte. Anais... Belo Horizonte: UFMG, 2013.

FARRUGIA, Francis. Une brève histoire des temps sociaux: Durkheim, Halbwachs, Gurvitch. Cahiers Internationaux de Sociologie, 1999, v. 106, p. 95-117. p. 115.

FONSECA, M.C.L. O patrimônio em processo: trajetória da política federal de preservação no Brasil. Rio de Janeiro, UFRJ/Iphan, 1997.

GURVITCH, Georges. The spectrum of social time. Dordrecht: D. Reidel. 1964.

HALL, Stuart. A identidade cultural na pós modernidade. $11^{\circ} \mathrm{ed}$. Rio de Janeiro: DP\&A, 2006.

HOBSBAWM, Eric. A Invenção das Tradições. In: HOBSBAWM, Eric; RANGER, Terence (orgs). A Invenção das Tradições. $6^{\circ}$ ed. Rio de Janeiro: Paz e Terra, 1997.

LACLAU apud HALL, Stuart. A identidade cultural na pós modernidade. $11^{\circ} \mathrm{ed}$. Rio de Janeiro: DP\&A, 2006.

MADUREIRA, Mariana Alves. A construção do Largo das Forras como patrimônio. Dissertação (Mestrado Arquitetura e Urbanismo). Universidade de São Paulo, 2011 MORAES, Eduardo Jardim de. Modernismo revisitado. Estudos Históricos, Rio de Janeiro, v. 1, n. 2, p. 220-238, dez. 1988.

NORA, Pierre. Les lieux de mémoire. Paris: Gallimard, 1997.

NORA, Pierre. Entre memória e história: a problemática dos lugares. Projeto História, v. 10, 1993.

NEVES, Rodrigo; CARNEIRO, Eder J. Empreendedorismo e marketing urbano: a mercadorização do centro "histórico" de Tiradentes, Minas Gerais, na ótica do turismo. Cenário, v. 2, n. 2, p. 65-81, 2014.

ONO, Maristela. Design e Cultura: sintonia essencial. Curitiba: Edição da autora, 2006.

RIBEIRO, Monica Cristina. Arqueologia modernista: viagens e reabilitação do primitivo em Mário e Oswald de Andrade. Dissertação (Mestrado em Antropologia Social), Universidade Estadual de Campinas, 2005. 
RIBEIRO, José Luiz. BRAGA, Humberto Fois. Espaços identitários na teledramaturgia. In: COUTINHO, Iluska; FIGUEIRA, Paulo Roberto (org.) Identidades midiáticas. Rio de Janeiro: Ed.:E-papers, 2009.

SANTOS, Cecilia Rodrigues dos. Novas fronteiras e novos pactos para o patrimônio cultural. São Paulo em perspectiva, v. 15, n. 2, p. 43-48, 2001. p.46

VELLOSO, Mônica. A brasilidade verde-amarela: nacionalismo e regionalismo paulista. Estudos Históricos, Rio de Janeiro, v. 6, n. 11, p. 89-112, jul. 1993.

\section{OUTRAS FONTES}

ARTES VERTENTES. Desenvolvido por Minas Online LTDA, 2012. Apresenta o festival Artes Vertentes. Disponível em: < http://www.artesvertentes.com/home/1> BRASIL. Ministério do Turismo. Plano Nacional de Turismo 2018-2022: mais emprego e renda para o Brasil. Disponível em:〈http://www.turismo.gov.br/images/mtur-pnt-web2.pdf $>$

CATÁlOGO Mostra de Cinema. $20^{\circ}$ Edição, 2017

ESTADO DE MINAS. Partiu Tiradentes: começa amanhã a $21^{\mathrm{a}}$ Mostra de Cinema na cidade histórica mineira. Portal Uai. Tiradentes, 18 jan. 2018. Disponível em: <https://www.uai.com.br/app/noticia/turismo/2018/01/18/noticiasturismo,220041/partiu -tiradentes-comeca-amanha-a-21-mostra-de-cinema-nacidade.shtml>

FARRUGIA, Francis. Une brève histoire des temps sociaux: Durkheim, Halbwachs, Gurvitch. Cahiers Internationaux De Sociologie, 1999, v. 106, p. 95-117. Disponível em <http://www.jstor.org/stable/40690808 >.

FARTURA Brasil. Desenvolvido por Arte Projeto Promoções LTDA, 2017. Apresenta o festival Fartura de Tiradentes. Disponível em: < http://farturabrasil.com.br/blogfestivais/2018-festival-fartura-tiradentes/festivais/2018-festival-fartura-tiradentes/>) FIEMG.. Apresenta informações sobre o Centro Cultural SESIMINAS Tiradentes. 2013. Disponível em: $\leq$ https://www7.fiemg.com.br/sesi/centro-decultura/tiradentes/sobre> Acesso em: 01 Set. 2018.

HALLAK, Raquel. Set, 2018a. Belo Horizonte: sede da Universo Produção. Entrevista concedida a AUTOR

JUSTINO, Ralph. Entrevista a Torres,. ViverBrasil. Tiradentes, 06 de fev. de 2015. PIRES, Pablo. Nov. 2018. Belo Horizonte. Entrevista concedida a AUTOR via e-mail.

ROMARIA Brasil. Notícias sobre a Igreja e turismo religioso. c2018. Disponível em: <http://romariabrasil.com.br/2017/03/tiradentes-mg/>

SCALZO, Mariana. Tiradentes vira cidade cenográfica na Rede Globo. Folha de São Paulo. São Paulo: 23 nov. 1997

TORRES, Fernando. Ralph Justino. ViverBrasil. Tiradentes, 06 de fev. de 2015.Disponível: $<$ http://www.revistaviverbrasil.com.br/plus/modulos/listas/?tac=notici as-ler\&id=534\#.XDzpMc9Kj-a $>$ 